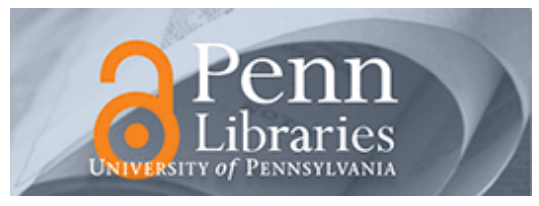

University of Pennsylvania

ScholarlyCommons

Management Papers

Wharton Faculty Research

$1-2015$

\title{
Partnering in a Haze: Interdependence Misspecification and Firm Performance in Strategic Alliances
}

\author{
Shiva Agarwal \\ University of Pennsylvania \\ Vikas A. Aggarwal \\ University of Pennsylvania \\ Harbir Singh \\ University of Pennsylvania
}

Follow this and additional works at: https://repository.upenn.edu/mgmt_papers

Part of the Management Sciences and Quantitative Methods Commons

\section{Recommended Citation}

Agarwal, S., Aggarwal, V. A., \& Singh, H. (2015). Partnering in a Haze: Interdependence Misspecification and Firm Performance in Strategic Alliances. Academy of Management Proceedings, http://dx.doi.org/ 10.5465/AMBPP.2015.17019abstract

This paper is posted at ScholarlyCommons. https://repository.upenn.edu/mgmt_papers/190

For more information, please contact repository@pobox.upenn.edu. 


\title{
Partnering in a Haze: Interdependence Misspecification and Firm Performance in Strategic Alliances
}

\begin{abstract}
We examine the implications for firm performance of managers having only a partial understanding of the true nature of their inter-firm interdependence. While operating with such ex-ante uncertainty regarding inter-firm interdependency is common when selecting an approach to governing an alliance relationship, the literature offers limited guidance as to the performance implications of such "misspecifications." We employ an agent-based simulation to model inter-firm decision making in a context where firms have either under- or over-specified views of their inter-firm interdependencies. Consistent with intuition, firm performance declines with interdependence misspecifications. We find, however, interesting variation in this effect across alternate governance modes and across levels of actual interdependency. We also find that interdependence misspecifications have differing effects on exploration and coordination, leading to tradeoffs between performance and other alliance objectives.
\end{abstract}

\section{Keywords}

alliances, governance, simulation

\section{Disciplines}

Management Sciences and Quantitative Methods 


\title{
PARTNERING IN A HAZE: \\ INTERDEPENDENCE MISSPECIFICATION AND FIRM PERFORMANCE IN STRATEGIC ALLIANCES
}

\author{
Shiva Agarwal \\ The Wharton School \\ University of Pennsylvania \\ shivaaga@wharton.upenn.edu \\ Vikas A. Aggarwal \\ INSEAD \\ Fontainebleau, France \\ vikas.aggarwal@insead.edu \\ Harbir Singh \\ The Wharton School \\ University of Pennsylvania \\ singhh@wharton.upenn.edu
}

December 2015

\begin{abstract}
We examine the firm performance implications of managers having an incorrect representation of their inter-firm task interdependencies in the context of alliance relationships. Although uncertainty regarding inter-firm interdependence is common in practice when structuring alliances, prior literature provides limited evidence on the firm performance implications of such "misspecifications." We employ a computational model to examine firm performance in an alliance context where firms have either under- or over-specified views of their inter-firm interdependencies. We find that firm performance declines with greater misspecification, with variation in this effect across alliance governance modes and across levels of actual interdependence. In addition, we find that interdependence misspecifications have differing effects on exploration and coordination, leading to tradeoffs between performance and these other non-performance alliance objectives.
\end{abstract}

Keywords: Strategic alliances; interdependence; coordination; exploration; NK-model 


\section{INTRODUCTION}

The strategic alliance literature points to inter-firm task interdependencies as a key link between alliance governance choice and firm performance (Gulati and Singh, 1998; Aggarwal, Siggelkow and Singh, 2011; Reuer and Devarakonda, 2015). Alliances involve the need to coordinate interdependencies across organizational boundaries (Hamel, Doz and Prahalad, 1989; Ring and Van de Ven, 1992), as well as the need to select governance mechanisms for inter-firm decision making (Aggarwal et al., 2011; Reuer and Devarakonda, 2015). The nature of inter-firm interdependence has been shown to influence governance mode choice (Kale and Puranam, 2004; Villalonga and McGahan, 2005) as well as the performance implications of this choice (Sampson, 2004; Mayer and Teece, 2008).

Prescriptive managerial advice stemming from this stream of the extant alliance literature generally makes the implicit assumption that in the course of deciding on a mode of governance, allying firms are "correct" in their representations of inter-firm interdependencies. In practice, however, managers often enter into alliances with an imperfect ex ante understanding of their true patterns of inter-firm interdependence (Haspeslagh and Jemison, 1991; Doz, 1996). This makes selection of a "correct" structure likely to be an unrealistic assumption. Our aim in this paper is thus to better understand the implications of relaxing the assumption that managers correctly understand inter-firm interdependencies when selecting an alliance governance mode. We focus on two forms of such interdependence misspecifications-over-specification and under-specification - analyzing how these incorrect managerial representations of inter-firm task interdependencies influence firm performance in an alliance setting, under varying interdependence and governance mode conditions. 
A small set of studies lends credence to the notion that managers do not have a fully correct understanding of their inter-firm task interdependencies when entering into alliances (Doz, 1996; Sosa, Eppinger and Rowles, 2004; Gokpinar, Hopp and Iravani, 2010). Although these studies have made important strides in expanding our understanding of the role of interdependence misspecifications, relatively little large-sample empirical research has addressed this issue (many of these studies are single case-based). One reason for the lack of research on this topic is the difficulty in measuring managers' ex-ante understanding of interdependencies. We consequently have very little understanding of the relative performance implications of different forms of interdependence misspecifications. To remedy this gap we develop a computational model that allows us to simulate managers' understanding of underlying task structures under different scenarios. This approach, we believe, offers a first step in pushing the literature toward a deeper understanding of how interdependence misspecifications influence firm performance in the context of alternate governance mode choices.

A key benefit of employing a computational model is that such models naturally overcome the limitation of not being able to observe counterfactuals, a critical constraint in empirical work. Examining the antecedents of alliance governance choice (e.g., Kogut and Singh, 1988; Hennart and Reddy, 1997; Dyer, Kale and Singh, 2004; Villalonga and McGahan, 2005), for example, very often relies on observing only realized transactions. A computational modeling approach allows us to develop insights by creating counterfactuals and specifying scenarios that are difficult (or impossible) to observe empirically.

We build on a rich body of work that has used computational methods to develop insights into issues in strategy (e.g. Levinthal, 1997). Such an approach enables us to abstract away from industry and firm-level factors such as resource complementarity, trust, and prior experience 
(Anand and Khanna, 2000; Kale, Dyer and Singh, 2002), and to focus instead on isolating the performance effects of errors associated with task interdependence structure assessment. In particular, we model various task interdependence structures and their associated errors, a goal that would not be possible to accomplish with empirical methods alone. ${ }^{1}$

Our results lead to several sets of insights. First, we find that interdependence misspecifications lead to a loss in firm value, with the relative magnitude of this loss varying by governance mode. Across-mode differences further suggest that normative advice regarding governance mode selection in alliances should be conditional on the relative level of ex-ante managerial certainty regarding the nature of inter-firm interdependence. Second, we find that increases in the actual (correct) level of interdependence reduce the underperformance penalty associated with interdependence misspecifications. Finally, we find that under- and overspecification influence alliance performance through their effect on the extent of exploration and the magnitude of coordination failures experienced by the firms in the alliance. While overspecification increases both exploration and coordination failures, under-specification decreases these two effects. The relative magnitude of the two effects explains the resulting impact on firm performance. When exploration and coordination itself are outcomes of interest in an alliance setting, our insights further point to the possibility of a tradeoff between performance and nonperformance outcomes, which may condition alliance governance mode choice.

In the next section we briefly highlight the literature which serves to motivate and frame our research question. In the subsequent sections we detail our computational model and associated analyses, with the aim of more deeply understanding the implications of

\footnotetext{
${ }^{1}$ Our study complements recent work examining misspecification of interdependencies in a single firm setting (Martignoni, Menon and Siggelkow, 2015). This work differs from ours in important ways, with one key difference being that Martignoni et al. (2015) focus on misspecification in a single-firm setting (versus an inter-firm setting like ours in which governance mode issues are paramount).
} 
interdependence misspecifications for firm performance in an alliance setting. We end by discussing the implications of our study for theory and for future research.

\section{MOTIVATING LITERATURE}

Alliances are complex inter-organizational relationships with high failure rates (Kale, Dyer and Singh, 2002; Kale and Singh, 2009; Lunnan and Haugland, 2008). A key challenge in an alliance context is governing the joint set of activities of the partnering firms. Recent work on alliance governance has underscored the importance of coordination among partner firms as a critical determinant of relationship success (e.g, Gulati and Singh, 1998; Gulati, Lawrence and Puranam, 2005; Reuer and Arino, 2007). Coordination is often necessary as partners must engage in joint tasks without the benefits of the structures and systems available in traditional hierarchies (Gulati and Singh, 1998). Difficulties arise from decomposing tasks and from ensuring the division of labor outside organizational boundaries, and coordination challenges persist even with perfect alignment of self-interest among the interacting parties (Heath and Staudenmayer, 2000; Kretschmer and Puranam, 2008).

While firms can address coordination challenges through a variety of mechanisms, including the use of detailed contracts that specify tasks, roles and responsibilities (Mayer and Argyres, 2004; Carson, Madhok and Wu, 2006; Reuer and Arino, 2007), contingency plans and responses (Ring and Van de Ven, 1994), and information sharing and feedback (Argyres and Mayer, 2007), explicit governance mechanisms are an over-arching channel through which coordination challenges are often resolved in alliance settings (Gulati and Singh, 1998). Interfirm interdependencies influence both the nature of the desired alliance governance structure, as well as the consequent performance of the relationship in the context of such a structure (Gulati 
and Singh, 1998; Mayer and Teece, 2008; Aggarwal et al., 2011; Reuer and Devarakonda, 2015; Kim, Zhao and Anand, 2015).

What are the implications of employing particular alliance governance structures when interdependencies are not correctly understood by managers? Though the literature on this question is limited, as the typical assumption is one of perfect knowledge regarding the nature and extent of task interdependencies (which in turn dictates appropriate governance structure choice), several studies have used case examples to illustrate the consequences of incorrect ex ante assessments of such interdependencies (e.g. Doz, 1996; Sosa et al., 2004; Gopkinar et al., 2010). In a study of the R\&D alliance between Ciba Geigy and Alza to develop a drug called OROS, for example, Doz (1996) finds that the allying firms started with an incorrect understanding of the nature of interdependencies among their underlying tasks. Their assumption was that the alliance would involve a simple "handover" of the drug from Alza to Ciba Geigy. In reality, however, the alliance required a high level of coordination between the downstream functions of both firms. Over the course of the alliance, as the firms realized the need for tighter coordination, they then ended up over-specifying the level of interdependence, selecting a governance structure that provided greater levels of coordination than actually required. As a consequence of the firms' interdependence misspecifications (and sub-optimal governance choices), joint development of the drug was slowed, and the alliance failed to meet its intended objectives.

Under-specified representations of task interdependencies can likewise be problematic. Sosa et al. (2004; 2007) address the under-specification issue in their study of a large commercial aircraft engine project. They find that a significant number of interdependencies between sub-systems were invisible to system architects. As a consequence, system architects 
did not set up appropriate structures to deal with underlying interdependencies, with the misalignment in structure and task interdependence resulting in significant cost and program delay.

Despite the fact that over- or under-specification of inter-firm task interdependencies is likely to be common in practice across many types of inter-organizational relationships, there is little systematic evidence in the literature (with the exception of a small set of case-based examples, two of which we mention above) as to how interdependence misspecification might affect the performance of firms, particularly under alternate modes of governing the alliance relationship itself. Our methodological approach in this paper, therefore, is to employ a computational model to investigate the link between misspecified levels of interdependence and alliance performance in a systematic manner. This approach enables us to develop a set of theoretical insights that might then serve as the basis for future empirical research. We turn to the details of our computational model in the next section.

\section{MODEL}

\section{Tasks and interdependencies}

We draw on the NK approach to modeling firm decision making (Kauffman, 1993, Levinthal, 1997), which conceptualizes firms as consisting of a set of inter-related activities, N, that can represent various organizational decisions such as those related to firm strategy, organizational form, product design, and so forth (Rivkin, 2000). ${ }^{2}$ The canonical NK model assumes that these $\mathrm{N}$ activities are interrelated so that a change in one activity affects the payoff to the other $\mathrm{K}$ activities. Firm performance is based on the unique configuration of these $\mathrm{N}$ activities, with the

\footnotetext{
2 We use the term "activities" interchangeably with "choices" and "tasks" throughout this paper.
} 
topography ("ruggedness") of the performance landscape determined by the degree of interaction among the firm's activities (Levinthal, 1997).

We build on Aggarwal et al. (2011), who extend the canonical NK approach to a twofirm alliance setting. In this model there are two firms, Firm 1 and Firm 2, each of which makes decisions over a set of binary activities denoted by $F_{1}$ and $F_{2}$. A subset of the activities of each firm is considered to be part of the alliance relationship (the "alliance activities"), denoted by $A_{i}$, while the remainder of the activities are outside the scope of the alliance (the "non-alliance activities"), denoted by $N_{i}$. Firm 1's activities are thus denoted by $F_{1}=\left\{N_{1}, A_{1}\right\}$ while Firm 2's activities are denoted by $F_{2}=\left\{N_{2}, A_{2}\right\}$. The two-firm system we model consists of a total of 12 activities, each of which is denoted by $d_{j}$, with $j$ running from 1 to $12 .{ }^{3}$ Figure 1 illustrates the allocation of each of the $d_{j}$ activities to the four activity sets $\left\{N_{1}, A_{1}, A_{2}, N_{2}\right\}$. For Firm 1 , for example, the non-alliance activities are represented by $N_{1}=\left\{d_{1}, d_{2}, d_{3}, d_{4}\right\}$ and the alliance activities are represented by $A_{1}=\left\{d_{5}, d_{6}\right\}$. Interdependencies among particular activities, which can be either intra-firm or inter-firm, are indicated with an " $\mathrm{X}$ ".

\section{[INSERT FIGURE 1 HERE]}

We then consider five different patterns of interdependence, as illustrated in Figure 2, each of which contains a different set of interdependencies among the four activity sets described in Figure 1. We select these patterns in order to model the characteristics of a broad range of interdependence forms. The patterns not only increase in the overall level of interdependence, but each successive pattern introduces a particular class of interdependence among the activity sets $\left\{N_{1}, A_{1}, A_{2}, N_{2}\right\}$ (e.g., going from Pattern 1 to Pattern 2 introduces interdependencies within the alliance activities) so that we can more easily isolate the implications of interdependencies of

\footnotetext{
3 This value for N is consistent with prior NK literature (e.g., Rivkin and Siggelkow, 2007; Aggarwal et al., 2011).
} 
different types. While these patterns are certainly not exhaustive, they collectively enable us to conduct a set of analyses that can generate insights into the mechanisms underlying our core research question around the impact of interdependence misspecifications.

Pattern 1, which we refer to as fully decomposable, has interactions only within each of the four activity subsets $\left\{N_{1}, A_{1}, A_{2}, N_{2}\right\}$ : the activities within the $N_{1}$ subset only affect other activities in $N_{1}$, and the same holds for activities within $A_{1}, A_{2}$ and $N_{2}$. In Pattern 2, pure alliance interaction, we introduce interactions within each of the sets of alliance activities of both the firms (i.e., within $A_{1}$ and $A_{2}$ ). In Pattern 3, firm own-alliance interaction, we introduce interactions within the firm's own non-alliance and alliance activities so that activities within $N_{1}$ interact with activities within $A_{1}$, and activities within $N_{2}$ interact with activities within $A_{2}$. In Pattern 4, firm partner-alliance interaction, the alliance activities of one firm interact with the non-alliance activities of the partner (activities within $A_{1}$ interact with activities within $N_{2}$, and activities within $A_{2}$ interact with those of $N_{1}$ ). And finally, for Pattern 5, full interdependence, there is complete interdependence, with all activities interacting with one other.

\section{[INSERT FIGURE 2 HERE]}

\section{Performance landscapes}

Each unique configuration of the $\mathrm{N}$ activities in the two-firm system (in which, as discussed above, the full set of $\mathrm{N}$ activities is divided into the subsets $\left.\left\{N_{1}, A_{1}, A_{2}, N_{2}\right\}\right)$ has associated with it a particular performance level. To create the performance landscape we follow the standard approach in the NK literature (e.g. Levinthal, 1997; Rivkin 2000): for each of the $N$ activities, $d_{i}$, in the system, we define a contribution value function $C_{i}$. Each $C_{i}$ takes as parameters the state (either 0 or 1 ) of $d_{i}$, together with the state of the $k_{i}$ other policies with which $d_{i}$ interacts (these interactions are defined, as described above, by the interaction matrix associated with the 
particular interdependence pattern being considered), and is initialized with a value drawn at random from a uniform $U[0,1]$ distribution for each possible combination of the various states of $d_{i}$ and its $k_{i}$ interacting policies. The set of $\mathrm{N}$ contribution value functions $C_{i}$ is defined at the outset, and remains unchanged as the simulation progresses.

The overall performance of the entire two-firm system for any given configuration of activities $d^{*}$ (i.e., the $\mathrm{N}$-dimensional vector of $d_{i}$ values) is the sum of the $\mathrm{N} C_{i}$ values for that particular configuration i.e. $\sum_{i=1}^{N} C_{i}$. We can define the performance of Firm 1 for a given $d^{*}$ as the sum of the contribution values of the activities specific to the firm itself, plus a portion, $\alpha$, of the alliance activities (we set $\alpha=0.5$ throughout). The performance of Firm 1, for example is $\sum_{i=1}^{4} C_{i}\left(d^{*}\right)+\alpha \sum_{i=5}^{6} C_{i}\left(d^{*}\right)$. To reduce statistical artifacts we follow the commonly employed approach in the NK literature in which the reported performance values are normalized by dividing the raw performance by the performance value at the highest peak in the landscape (see e.g., Rivkin and Siggelkow [2003]).

\section{Interdependence misspecifications}

Modeling misspecifications in managerial representations of task interdependencies requires that we model not only the true underlying interaction matrix among the firms, but also that we model the misspecified representation of the interaction matrix that is taken into account by managers as they make decisions. We do so by modeling two matrices, with the true matrix used to determine the actual performance that managers observe as a consequence of their choices, and the misspecified matrix used to determine the choice that managers actually make as they search the landscape.

More formally, we define two interaction matrices. The first interaction matrix, $M_{0}$, represents the true structure of the underlying pattern of inter-firm task interdependence, and is 
used to determine the performance landscape as discussed in the prior section. The second interaction matrix, $M_{1}$, represents firms' own representation of the inter-firm task interdependencies, and can differ from the true matrix $M_{0}$. The performance landscape for $M_{1}$ is derived from the true performance landscape $M_{0}$ to ensure that the (potentially misspecified) performance values are correlated with the true performance values via the processes described later in this section.

Firms search by evaluating alternatives and making choices with respect to their activities based on a set of governance structures which we describe in a subsequent section. In the process of evaluating alternatives and making changes to their activities $d_{i}$, the firms take into account performance values as determined by the (misspecified) interdependence matrix, $M_{1}$. Once a choice is made in any given period, however, the performance that firms actually experience is defined by performance values stemming from the (true) interdependence matrix, $M_{0}$. While searching for high performing configurations, firms compare the performance values of the alternatives based on the $M_{1}$ matrix with the observed performance of the current configuration based on the $M_{0}$ matrix.

Firms are said to have an under-specified view when the misspecified matrix $M_{1}$ has a lower degree of interdependence than the true matrix $M_{0}$; and firms are said to have an overspecified view when the misspecified matrix $M_{1}$ has a higher degree of interdependence than the true matrix $M_{0}$. For the purpose of our analysis we will consider misspecifications that differ by a single pattern difference as defined by the patterns in Figure 2. As an example, with a true Pattern 3 interdependence matrix (i.e., where $M_{0}$ is based on Pattern 3), under-specification is defined as a situation where there is an $M_{1}$ based on Pattern 2, while over-specification is defined as a situation where there is an $M_{1}$ based on Pattern 4 . 
In the remainder of this section we discuss the processes for calculating the performance values of the landscapes as a function of the under- or over-specification of the $M_{1}$ pattern. The performance levels for $M_{1}$ (whether under- or over-specified) are derived from the $M_{0}$ performance levels. To accomplish this we first define the performance landscape for $M_{0}$ via the process described in the previous section; and we then derive the performance landscapes for the under- and over-specified cases using the procedures described next.

Under-specified interdependence matrix $\boldsymbol{M}_{1}$. What is the procedure we use to construct a performance landscape for an under-specified matrix? The performance values of the underspecified landscape should be correlated with the true landscape in such a way that the underspecified landscape appears to be a slightly "blurry" (or less rugged) version of the true landscape. How do we accomplish this? When the matrix $M_{1}$ is under-specified, each decision $d_{i}$ is affected by $\bar{k}_{i}$ other decisions, with $\bar{k}_{i}<k_{i}$, where $k_{i}$ is the number of interdependencies associated with $d_{i}$ in the true matrix $M_{0}$. In order to calculate the performance landscape for $M_{1}$ we take averages of the contribution values from the true interaction matrix $M_{0}$ for each fixed configuration of $d_{i}$ and its $\bar{k}_{i}$ interacting choices, an approach consistent with Gavetti and Levinthal (2000).

We can illustrate this process with an example. Assume that in the true matrix $M_{0}$ a particular activity $d_{1}$ interacts with activities $d_{2}, d_{3}$, and $d_{4}$. Also assume that in the misspecified matrix $M_{1}$ the activity $d_{1}$ is represented by managers as interacting only with activity $d_{2}$. The performance landscape $M_{1}$ thus requires that we generate contribution values for each unique combination of the $d_{1}$ and $d_{2}$ activities. For ease of notation, let $C_{i}$ refer to the contribution value function for activity $d_{i}$ for the true matrix $M_{0}$. Furthermore, let the four arguments of $C_{i}()$ refer to the states (which can be either 0 or 1) of each of the activities $d_{1}$ 
through $d_{4}$. Thus $C_{1}(0,0,0,0)$ refers to the contribution value assigned to the true $\left(M_{0}\right)$ matrix for activity $d_{1}$ where activities $d_{1}$ through $d_{4}$ are all set to 0 . In our example, we would define the contribution values for $d_{1}$ in the misspecified matrix $M_{1}$ for each of the four possible configurations of the $d_{1}$ and $d_{2}$ activities as follows:

$$
\begin{aligned}
& d_{1}=0 \text { and } d_{2}=0 \text { : Average }\left\{C_{1}(0,0,0,0), C_{1}(0,0,0,1), C_{1}(0,0,1,0), C_{1}(0,0,1,1)\right\} \\
& d_{1}=0 \text { and } d_{2}=1 \text { : Average }\left\{C_{1}(0,1,0,0), C_{1}(0,1,0,1), C_{1}(0,1,1,0), C_{1}(0,1,1,1)\right\} \\
& d_{1}=1 \text { and } d_{2}=0 \text { : Average }\left\{C_{1}(1,0,0,0), C_{1}(1,0,0,1), C_{1}(1,0,1,0), C_{1}(1,0,1,1)\right\} \\
& d_{1}=1 \text { and } d_{2}=1 \text { : Average }\left\{C_{1}(1,1,0,0), C_{1}(1,1,0,1), C_{1}(1,1,1,0), C_{1}(1,1,1,1)\right\}
\end{aligned}
$$

Over-specified interdependence matrix $M_{1}$. Having discussed the procedure for constructing an under-specified performance landscape, we turn next to the procedure for constructing the performance values of an over-specified landscape. In this case, rather than being a slightly "blurry" (or less rugged) version of the true landscape (as it was in the underspecified case), the over-specified landscape can be thought of as a more "granular" (or more rugged) version of the true landscape.

How do we accomplish this? When the matrix $M_{1}$ is over-specified, each activity $d_{i}$ is affected by $\overline{\bar{k}}_{i}$ other activities, with $\overline{\bar{k}}_{i}>k_{i}$ (where $k_{i}$ is the number of interdependencies associated with $d_{i}$ in the true matrix $M_{0}$ ). This implies that for each unique combination of $d_{i}$ and the $k_{i}$ other activities affecting it in the baseline $M_{0}$ matrix, there are $2^{\bar{k}_{i}-k_{i}}$ additional contribution values in the $M_{1}$ matrix that must be created to account for the additional $M_{1}$ matrix interdependencies. To generate these additional contribution values we follow the following process. First, we generate $2^{\bar{k}_{i}-k_{i}-1}$ random numbers $\varepsilon_{j}$ from the uniform distribution $U[0, a]$, where $a$ is $\min \left(c_{i}, 1-c_{i}\right)$, and $c_{i}$ is the particular contribution value for $d_{i}$ for the specific configuration of $d_{i}$ and the $k_{i}$ other policies affecting it (note that $c_{i}$ is based on the $C_{i}$ function 
that defines the landscape for the $M_{0}$ matrix). Second, for each random number $\varepsilon_{j}$ we generate two contribution values $c_{i j 1}=c_{i}+\varepsilon_{j}$ and $c_{i j 2}=c_{i}-\varepsilon_{j}$. Finally, we randomly assign $c_{i j 1}$ and $c_{i j 2}$ to the additional $2^{\overline{\bar{k}}_{i}-k_{i}}$ activity combinations for which we need the additional contribution values. Constructing the landscape for the over-specified matrix in this way allows us to ensure that the true and misspecified landscapes are correlated with one another in the same way as they are in the under-specified case. More specifically: under-specifying (by one pattern) an overspecified (by one pattern) landscape results in the original (correct) landscape.

We can illustrate the over-specification procedure with an example. Assume that in the true matrix $M_{0}$ the activity $d_{1}$ interacts with $d_{2}$ and $d_{3}$, while in the over-specified representation $M_{1}$, in addition to these interactions there are two additional interactions, with activities $d_{4}$ and $d_{5}$. In this case it is necessary to define four additional contribution values for each possible configuration of $d_{1}, d_{2}$ and $d_{3}$. In the case where the activity configuration of $\left(d_{1}, d_{2}, d_{3}\right)$ is $(1,0,0)$, for example, we need to construct contribution values for activity $d_{1}$ where the $\left(d_{1}, d_{2}, d_{3}, d_{4}, d_{5}\right)$ values take on the following set of four possible configurations: $(1,0,0,0,0)$, $(1,0,0,0,1),(1,0,0,1,0)$, and $(1,0,0,1,1)$. To do this we start with $c_{1}=C_{1}(1,0,0)$. That is, we start with $c_{1}$, which is the specific contribution value in the $M_{0}$ matrix for the $d_{1}$ activity where the configuration of $\left(d_{1}, d_{2}, d_{3}\right)$ is $(1,0,0)$. We define $a=\min \left(c_{1}, 1-c_{1}\right)$, and then generate two error terms $\varepsilon_{1}$ and $\varepsilon_{2}$ from the uniform distribution $U[0, \alpha]$. These two error terms then allow us to generate the four contribution values $c_{11}=c_{1}+\varepsilon_{1}, c_{12}=c_{1}-\varepsilon_{1}, c_{13}=c_{1}+\varepsilon_{2}$, and $c_{14}=c_{1}-\varepsilon_{2}$, which we then assign at random to the four configurations noted above, $(1,0,0,0,0),(1,0,0,0,1),(1,0,0,1,0)$, and $(1,0,0,1,1)$. E.g., if $C_{1}^{M_{1}}\left(d_{1}, d_{2}, d_{3}, d_{4}, d_{5}\right)$ represents the function that maps the particular configuration of $d_{1}$ through $d_{5}$ to a particular contribution value for $d_{1}$ in the $M_{1}$ matrix, then after generating the contribution values through the process 
described above, the random allocation could generate the following: $C_{1}^{M_{1}}(1,0,0,0,0)=c_{11}$; $C_{1}^{M_{1}}(1,0,0,0,1)=c_{13} ; C_{1}^{M_{1}}(1,0,0,1,0)=c_{14} ;$ and $C_{1}^{M_{1}}(1,0,0,1,1)=c_{12}$.

\section{Governance modes}

We turn next to the governance modes that determine how agents in our model search the performance landscape. We draw on Aggarwal et al. (2011), considering four governance modes that represent varying points along the spectrum of alliance integration (Kogut and Singh, 1988; Hennart and Reddy, 1997; Dyer et al., 2004; Villalonga and McGahan, 2005). At the opposite ends of the spectrum we have what we refer to as the modular and integrated modes of governance. As hybrid forms we consider what we refer to as the self-governing alliance and ratification modes. We describe each of these modes in detail in the remainder of this section.

In the modular mode of governance both firms make choices simultaneously within a given period and only consider the profits associated with the particular activities within their scope. We model a 12 activity system, with performance values normalized by the total value of the system at the highest peak of the landscape (performance at the landscape peak is denoted by $\left.\Pi^{*}\right)$. In the modular mode Firms 1 and 2 control their respective alliance and non-alliance activities independently, with each firm thus controlling 6 of the 12 activities in the system. In each period Firm 1 evaluates alternatives for activities $d_{1}$ through $d_{6}$ based on the expected value of the configuration stemming from $M_{1}$, comparing these alternatives against the realized performance from the prior period as determined by $M_{0}$, and selecting a choice if it increases their expected performance. Firm 2 does the same for its own set of policy choices.

More precisely, in the modular mode, Firm 1 evaluates alternatives based on its expected profit, $\sum_{i=1}^{6} C_{i}^{M_{1}}\left(\bar{d}_{t}\right) / \Pi^{*}$, comparing this against the prior period realized performance, 
$\sum_{i=1}^{6} C_{i}^{M_{0}}\left(\bar{d}_{t-1}\right) / \Pi^{*}$. Similarly, Firm 2 evaluates its alternatives based on its expected profit $\sum_{i=7}^{12} C_{i}^{M_{1}}\left(\bar{d}_{t}\right) / \Pi^{*}$, comparing this against $\sum_{i=7}^{12} C_{i}^{M_{0}}\left(\bar{d}_{t-1}\right) / \Pi^{*}$. In this notation $C_{i}^{M_{0}}$ and $C_{i}^{M_{1}}$ respectively represent the contribution values for activity $d_{i}$ based on the $M_{0}$ and $M_{1}$ matrices respectively. Vector $\bar{d}_{t}$ refers to the configuration of the activities being evaluated in the current period, while vector $\bar{d}_{t-1}$ refers to the existing configuration of activities, as of the end of the prior period. Firm 1 and Firm 2 can change up to two activities in any given period, and agents for each firm evaluate all possible alternatives when making decisions in a given period. For each agent, and for each alternative being considered by each agent, the vector $\bar{d}_{t}$, which represents the vector being evaluated by the agent, is thus allowed to differ from the prior round's realized configuration $\bar{d}_{t-1}$ by up to two activities. ${ }^{4}$

While the modular mode can be conceptualized as a simple case of an arms-length relationship where both firms work independently with full control of their activities, the integrated mode lies at the other end of the spectrum. In the integrated mode Firms 1 and 2 operate as a single entity that makes decisions with respect to all 12 policy choices. Examples of integrated governance structures can be found in long-term equity-based alliances where decision making is fully integrated, and where firms behave as if they were a single entity (e.g., the alliance between Renault and Nissan, in which there is an integrated governance structure under a single leadership).

\footnotetext{
4 Prior work has parameterized the number of activities that can be changed in any given period, as well as the number of alternatives considered, referring to these values as "search radius" and "alternatives" (Siggelkow and Rivkin [2005]; Aggarwal et al. [2011]). In our study we hold these parameters constant, allowing each agent to have a search radius of 2 , and to evaluate all possible alternatives associated with this search radius in any given period. We thus map to what Aggarwal et al. (2011) refer to as "Capability Level D". Our results and insights, however, are qualitatively similar and robust to variation in these parameters. For ease of exposition we report all results based on these fixed settings of "search radius" and "alternatives." Results on alternative settings are available upon request.
} 
In our model of the integrated mode, the single agent takes into account the total combined profit of Firms 1 and 2 when evaluating alternatives, comparing this against the profit from the prior round's full configuration. Formally, the quasi-integrated entity evaluates alternatives based on $\sum_{i=1}^{12} C_{i}^{M_{1}}\left(\bar{d}_{t}\right) / \Pi^{*}$, comparing these against $\sum_{i=1}^{12} C_{i}^{M_{0}}\left(\bar{d}_{t-1}\right) / \Pi^{*}$, where $\bar{d}_{t}$ is the vector being evaluated, which differs from the prior round's configuration $\bar{d}_{t-1}$ by up to two activities. Though profit is calculated at the level of the system, we can also report profit for each firm; since the firms are symmetric in our analyses, profit for each individual firm is simply $1 / 2$ of the the profit of the entire system.

In addition to the modular and integrated governance modes which lie on opposite ends of the governance spectrum, we consider two hybrid modes: self-governing alliance and ratification, in line with Aggarwal et al. (2011). In both cases the alliance function is managed independently by a third agent (e.g., a joint committee formed by both firms to manage the alliance). The agents for Firms 1 and 2 are responsible solely for their respective non-alliance activities ( $d_{1}$ through $d_{4}$ and $d_{9}$ through $d_{12}$ respectively), but in the process of evaluating alternatives and making decisions each takes into account their individual total profit, which for each firm is defined as the profit of the firm's non-alliance activities plus a portion, $\alpha$, of the profit from the alliance activities (we set $\alpha=0.5$ throughout). The alliance agent considers profit from only the alliance activities (i.e., $d_{5}$ through $d_{8}$ ) when evaluating alternatives and making decisions.

More precisely, with the self-governing alliance and ratification modes, in each period the Firm 1, Firm 2, and Alliance agents each make the following comparisons when evaluating alternatives, with each agent able to make up to two changes to the (four) activities under each of 
their individual purview (i.e., in each case the N-dimensional vector of binary values $\bar{d}_{t}$ differs from $\bar{d}_{t-1}$ by at most two activities):

Firm 1 compares: $\quad \sum_{i=1}^{4} C_{i}^{M_{1}}\left(\bar{d}_{t}\right) / \Pi^{*}+0.5 * \sum_{i=5}^{8} C_{i}^{M_{1}}\left(\bar{d}_{t}\right) / \Pi^{*}$ against: $\sum_{i=1}^{4} C_{i}^{M_{0}}\left(\bar{d}_{t-1}\right) / \Pi^{*}+0.5 * \sum_{i=5}^{8} C_{i}^{M_{0}}\left(\bar{d}_{t-1}\right) / \Pi^{*}$

Firm 2 compares: $\quad \sum_{i=9}^{12} C_{i}^{M_{1}}\left(\bar{d}_{t}\right) / \Pi^{*}+0.5 * \sum_{i=5}^{8} C_{i}^{M_{1}}\left(\bar{d}_{t}\right) / \Pi^{*}$ against: $\sum_{i=9}^{12} C_{i}^{M_{0}}\left(\bar{d}_{t-1}\right) / \Pi^{*}+0.5 * \sum_{i=5}^{8} C_{i}^{M_{0}}\left(\bar{d}_{t-1}\right) / \Pi^{*}$ Alliance compares: $\quad \sum_{i=5}^{8} C_{i}^{M_{1}}\left(\bar{d}_{t}\right) / \Pi^{*}$ against: $\sum_{i=5}^{8} C_{i}^{M_{0}}\left(\bar{d}_{t-1}\right) / \Pi^{*}$

Although the way the self-governing alliance and ratification modes compare alternatives is the same, the two modes differ in the level of independence and degree of oversight over the alliance agent. In the self-governing alliance mode, the alliance agent operates independently, without any oversight from the firms. In any given period the alliance agent makes its decisions. Firms 1 and 2 then select their policies simultaneously, taking into account the policy choice made by the alliance agent.

In the ratification mode, by contrast, in any given period the Firm 1 and Firm 2 agents decide on their activity set changes, followed by the alliance agent. Firm 1 and Firm 2 then have veto power over the activity changes suggested by the alliance agent. That is, before implementing any activity change, the alliance agent needs to have its proposed change ratified by the agents of the two firms. Ratification requires that both firms accept the proposed policy change, with a firm accepting any proposed policy change only if it does not reduce the firm's own profit. 


\section{ANALYSIS}

We model a 12-policy choice system of two firms, with four activity subsets $\left\{N_{1}, A_{1}, A_{2}, N_{2}\right\}$, sub-divided as depicted in Figure 1, and with patterns of interdependence as depicted in Figure 2. The model is symmetric for both firms such that the performance results of each are equal when run over a large number of landscapes. We thus focus on analyzing the difference in overall performance of the two-firm alliance system under varying combinations of interdependence pattern and governance structure. We are interested in situations of over- or under-specification, which we define as a single pattern higher or lower, respectively in interdependence (for example, with the patterns in Figure 2, over-specification for Pattern 3 would be Pattern 4, while under-specification for Pattern 3 would be Pattern 2). We assume that both firms and the alliance agent (in the case of self-governing alliance and ratification) have the same misspecified view of the underlying task structure. Each time period in the simulation consists of agents making a set of decisions with respect to their activities (per the mode governing their decisions as described in the previous section). We run the simulation for 200 periods on a particular landscape in order to observe the long-run performance of firms in the system, and then take an average over 10,000 different simulation runs in order to minimize the effects of any statistical artifacts.

\section{Performance implications of over- and under-specification}

As a starting point for our analysis we compare long-term performance outcomes, i.e. performance at the end of period 200, for the alliance system in the case of misspecification to the case where all the agents in the system have a correct understanding of their task interdependencies. We refer to the percentage decline in overall performance as the "value-loss" due to the misspecification of task interdependence. 
Over-specified case. We begin with the situation where the firm agents (and alliance agent in the case of the self-governing alliance and ratification modes) have an over-specified view of the underlying task structure. We consider performance for the four different forms of governance under the various interdependence patterns. Table 1A compares the performance outcomes of the four governance modes under Patterns 1 through 4 for firms with the overspecified view. We find that the average long-run performance for firms with an over-specified view decreases for all patterns. Pattern 1 has a lower value loss compared to the rest of patterns, due primarily to the difference in the additional number of interdependencies agents consider in the search landscape. ${ }^{5}$ Moving on to the rest of the patterns, we find that the overall value loss decreases as we move from Pattern 2 to Pattern 4. For example, for the modular governance mode, the overall value loss is $-18.6 \%$ for Pattern 2 as compared to $-14.8 \%$ for Pattern 4 . Similarly, for the self-governing alliance mode the overall value loss is $-15.0 \%$ for Pattern 2 whereas it is $-4.6 \%$ for Pattern 4. Further, for the ratification mode the overall value loss is $18.8 \%$ for Pattern 2 , while it is $-8.3 \%$ for Pattern 4 . For the integrated mode the overall value loss is $-20.0 \%$ for Pattern 2 and $-11.3 \%$ for Pattern 4.

Our findings on the effects of over-specification are consistent with intuition. The overall loss in value for the firm with an over-specified view is directly linked to the error introduced into the search process as a consequence of the over-specification. For example, in the case of Pattern 1, while searching for higher performance the firm assumes that the alliance activities of the two firms are interdependent, impacting its performance. In reality, however, the underlying task is fully decomposable, with no interdependence between the alliance activities of the two

\footnotetext{
${ }^{5}$ Pattern 1 differs from other patterns with respect to the total number of interdependencies that the agents consider in their search landscape (an additional 8 interdependencies with an over-specified view). For the other patterns the search landscape has an additional 32 interdependencies.
} 
firms. This misspecification of interdependence leads to an error in the search process, decreasing performance.

Under-specified case. We turn next to examining how under-specification affects the performance of both firms. Table 1B shows performance outcomes of the various modes under Patterns 2 through 5 for firms with the under-specified view. We find that under-specification leads to lower performance on average. Similar to the over-specification results we find that Pattern 2 has a lower value loss compared to the other patterns with under-specification, primarily due to the difference in the characteristics of interdependencies that agents consider to be missing in the case of Pattern 2 and the other patterns. ${ }^{6}$

In the under-specified case we also find that the overall value loss decreases as we move from Pattern 3 to Pattern 5. In fact, for Pattern 5, we find that the overall performance increases for the modular and self-governing alliance modes. For example, in the case of the modular governance mode, the overall value loss is $-19.1 \%$ for Pattern 3 as compared to a $7.8 \%$ gain for Pattern 5. Similarly, the overall value loss for Pattern 3 in the case of the self-governing alliance is $-17.3 \%$, while it is $-1.0 \%$ for Pattern 5. For other modes the overall value losses for Pattern 2 with the ratification and integrated modes are $-15.6 \%$ and $-21.6 \%$ respectively, while they are $2.5 \%$ and $-9.5 \%$ for Pattern 5 with the ratification and integrated modes.

We can then observe the governance structure that provides the highest performance level when agents have the correct view as compared to when they have a misspecified view. Interestingly, we find that misspecification of task structure often results in a different governance mode providing the optimal level performance. For example, the integrated

\footnotetext{
${ }^{6}$ Firms consider a total of 8 interdependencies within the alliance agent to be missing when considering the underspecified view of Pattern 2. For the rest of the patterns, firms consider their search landscape to have 32 fewer interdependencies as compared to that of the true landscape.
} 
governance mode provides the highest performance for Pattern 4 when firms have the correct view, while the self-governing alliance mode provides the highest performance with both underand over- specified views. On average, we find that the self-governing alliance mode provides the highest performance across patterns for both forms of misspecification (Pattern 1 with the over-specified view is an exception where the modular governance mode performs better). We turn to the mechanisms driving these results in the next section.

\section{[INSERT TABLES 1A AND 1B HERE]}

\section{Coordination failures and exploration as intermediate explanatory mechanisms}

To more deeply understand the reasons for the differences in value loss among the various interdependence pattern-governance mode combinations, we turn next to the mechanisms that may influence firm performance in an alliance setting, building on Aggarwal et al.'s (2011) discussion of the role of coordination and exploration in influencing the performance effects of alliance governance. Figure 3 illustrates the over-arching conceptual framework we explore in the remainder of this section: coordination failures and exploration achieved are intermediate measures that link misspecification, governance mode and level of interdependence with firm performance in an alliance setting.

\section{[INSERT FIGURE 3 HERE]}

Why do we focus in particular on the dimensions of coordination and exploration? Coordination concerns are pervasive in an alliance context (Litwalk and Hylton, 1962), influencing governance mode decisions (Gulati and Singh, 1998). The ability to effectively coordinate activities among alliance partners, moreover, influences alliance performance (Zollo, Reuer and Singh, 2002; Gulati, Lawrence and Puranam, 2005). In addition to effective coordination, exploration is a key determinant of alliance performance as well (Child, 2001; 
Grant \& Baden-Fuller, 2004; Lavie and Rosenkopf, 2006). We thus aim to understand how interdependence misspecifications, together with governance modes and actual patterns of interdependence, link to firm performance via the mediating effects of coordination and exploration.

Constructing the intermediate measures of coordination and exploration. We construct the measure, coordination failures, which we define, in any given period, to be the total number of incidences up to and including the current period in which firms (in total) experience a profit decline as compared to the previous period due to simultaneous decision making by the two firms. Total (Firm $1+$ Firm 2) profit can decline both because of simultaneous movement of the agents, as well as because of errors in the search process due to landscape misspecification. We isolate the former by stripping out situations of search-related error. ${ }^{7}$ For our analyses in this paper we consider coordination failures at period 200, which is the point at which the two-firm system has reached a steady-state level of performance.

We also construct the measure exploration achieved by calculating the total number of unique contribution values $\left(C_{i}\right.$ 's) evaluated by the agents in the system over time, normalized by the total number of possible contribution values that exist for the given landscape (Aggarwal $e t$ al., 2011). ${ }^{8}$ The evaluated and total contribution values used as inputs to our exploration achieved measure come from the true landscape $\left(M_{0}\right)$, and are based on the agents' search history on the misspecified landscape $\left(M_{1}\right)$. More precisely, for each policy configuration

\footnotetext{
7 Due to differences in the contribution values between the search $\left(M_{1}\right)$ and true $\left(M_{0}\right)$ landscapes, configurations leading to high performance on the search landscape may not lead to high performance on the true landscape. An agent using a misspecified landscape for search may commit to a policy configuration that can lead to a decline in performance on the true landscape. We refer to this decline in performance due to differences in contribution values between the true and search landscapes as "search-related error." We strip out such search-related errors from the measure of coordination failures so that the measure reflects only situations where agents simultaneously make a choice that may be correct for each firm individually, but that ends up being performance reducing for the total profits of both firms as a whole.

8 For instance, the total number of possible contribution values for Pattern 1 is 144 , and for Pattern 5 it is 49,152 .
} 
evaluated by the agents on the search landscape $\left(M_{1}\right)$ up to and including the focal period, we take the corresponding configuration on the true landscape $\left(M_{0}\right)$ and identify whether the contribution values for that policy configuration, as derived from the $M_{0}$ landscape, have been considered by the agents in the search process up to and including the focal period. ${ }^{9}$ We count the total number of such cases where a particular contribution value has been evaluated, and divide this by the total number of distinct contribution values based on $M_{0}$. As we do with coordination failures, we consider exploration achieved in the steady-state at period 200.

Implications of over-specification for intermediate measures. How does overspecification affect the intermediate measures of coordination failures and exploration? In the over-specified case the landscape searched by the agents becomes more rugged than that of the true landscape. Additionally, values of adjacent locations on the landscape are less correlated as compared to that of the true landscape. This increases the number of alternatives the agent considers, as well as the duration of the search process before an agent locks itself into a policy configuration. While this increase in the number of alternatives considered leads to a higher degree of exploration achieved, the increase in search time also leads to higher levels of coordination failure. With multiple agents searching the landscape at the same time, the chances of coordination failure increases as policies selected by one agent may not be optimal for the other. The degree of coordination failures between agents thus depends on the duration over which agents search the landscape simultaneously.

\footnotetext{
${ }^{9}$ Note that any given policy configuration will exist on both landscapes $\left(\mathrm{M}_{0}\right.$ and $\left.\mathrm{M}_{1}\right)$. However, whether or not the corresponding contribution values are "distinct" is a function of the interdependence structure of that landscape (which of course differs between $\mathrm{M}_{0}$ and $\mathrm{M}_{1}$ ). As an example, suppose we take a simple system in where there are only two possible binary policy choices $\left\{\mathrm{d}_{1}, \mathrm{~d}_{2}\right\}$. When an agent evaluates the move from the existing policy configuration $\{0,0\}$ to a new policy configuration $\{0,1\}$, the number of distinct contribution values she considers will differ depending on whether the two policy choices are interdependent or not. If they are interdependent, then there would be two unique contribution values, $\mathrm{C}_{1}(0,1)$ and $\mathrm{C}_{2}(0,1)$, which would be taken into account; if they are not interdependent, then only one unique contribution value, $\mathrm{C}_{2}(0,1)$ would need to be considered.
} 
We report the results of the effect of over-specification on exploration achieved and coordination failures in the middle two columns of Table 2A (falling under the heading "symmetric view"). As in Table 1 we compare the performance metric (in this case exploration achieved or coordination failures) for the misspecified case relative to the correctly-specified case at the end of period 200. The table shows that the overall degree of exploration achieved by the agents increases with the over-specified view. Furthermore, the effect of over-specification is more prominent at patterns with a higher degree of interdependence, and with the modular and self-governing alliance modes. In addition, agents with the over-specified view face a higher level of coordination failure. For example, under Patterns 3 and 4 with the self-governing alliance mode, coordination failures increase by $3.5 \%$ and $1.6 \%$ respectively.

Implications of under-specification for intermediate measures. How does underspecification affect the intermediate measures of coordination failures and exploration? In the under-specified case the search space for the agent is simplified. The agent searches on a landscape with a lower degree of interdependence that is consequently less rugged as compared to the true landscape. Each policy on the search landscape corresponds to a cluster of policies on the actual landscape. This simplification of the search landscape speeds the agent's search processes (e.g., Gavetti and Levinthal, 2000), enabling the agent to relatively quickly identify a peak with respect to its search landscape. Thus, the degree of exploration achieved with the underspecified-view decreases, as Table 2B (middle two columns, under the heading "symmetric view") reports. The increase in search speed is particularly helpful in reducing coordination failures: with an increase in search speed agents identify optimal performance configurations with relatively fewer activity changes, reducing the overall number of associated coordination failures. 


\section{[INSERT TABLES 2A AND 2B HERE]}

Concordance with conceptual framework. Having discussed the implications of misspecification for coordination and exploration, we now return to Figure 3, with the aim of testing the conceptual framework depicted there. To do so we construct a dataset based on our simulation results at period 200 with 320,000 observations: we run 10,000 trials for each combination of misspecification-pattern-governance mode combination; and we then employ seemingly unrelated regression (SUREG) to analyze the results, using the framework depicted in Figure 3. We estimate three equations simultaneously: (1) the impact of misspecification on exploration achieved; (2) the impact of misspecification on coordination failures; and (3) the impact of exploration achieved and coordination failures on total performance. Seemingly unrelated regression (SUREG) allows for correlation between the error terms of these equations (Zellner, 1962, 1963), a likely situation given the approach used to construct our dataset.

In our SUREG models the variable, misspecification, takes the value of one when the observation is under a misspecified view, and 0 otherwise. We estimate models for over- and under- specification separately. To control for the effects of patterns and governance modes we include dummy variables for these factors. The modular governance mode is used as the base mode against which to compare the effects of the other modes; and Pattern 2 is used as the base pattern against which to compare the effects of the other patterns. ${ }^{10}$

Estimated standardized coefficients for the two models (over- and under-specified) are reported in Table 3. We do not show $p$-values of the estimated coefficients to avoid redundancy, as all the $p$-values are less than 0.001 (with the exception of the effect of misspecification on

\footnotetext{
${ }^{10}$ Since we do not have any observations for Pattern 1 in the case of the under-specified view, and for Pattern 5 in the case of the over-specified view, we use Pattern 2 as the base pattern, as it is common across both forms of misspecification.
} 
coordination failures in the case of the over-specified view). As Model 1 shows, the coefficient of misspecification on exploration is positive, suggesting that over-specification of task structure is associated with higher exploration. On average, firms with the over-specified view tend to explore more by 0.10 standard deviation. Similarly, in Model 2, the coefficient of misspecification on coordination failures is negative, suggesting that under-specification is associated with fewer coordination failures. Though we do not find statistically significant effects of over-specification on coordination failures, we do find that under-specification increases coordination failures by 0.19 standard deviations. Furthermore, consistent with earlier research we find that the coefficient of exploration on overall performance is positive, and the coefficient of coordination failures on overall performance is negative, for both Model 1 and Model 2. We find that a standard deviation increase in coordination failures decreases overall performance by -0.21 and -0.37 standard deviations for over- and under-specification respectively. Similarly we find that a standard deviation increase in exploration increases overall performance by 0.38 and 0.45 standard deviations for over- and under-specification respectively.

\section{[INSERT TABLE 3 HERE]}

\section{Implications for governance mode choice: asymmetric view}

In a final set of analyses we consider the situation in which only one partner has either an underor over-specified view. The results of the "asymmetric" perspective on coordination and exploration outcomes are shown in the right two columns of Tables $2 \mathrm{~A}$ and $2 \mathrm{~B}$ (under the heading "asymmetric view"). The asymmetric view is one in which the focal firm has the correct representation, while the partner has the misspecified view. These results help address the question of what governance mode managers should choose (or rather, negotiate for ex ante), conditional on their assessment of their partners' likely representation of interdependencies. 
As Table 2A suggests, if managers believe their partner to be over-specified, higher levels of exploration can be obtained by selecting the modular governance mode, and coordination failures can be minimized by selecting the self-governing alliance mode. If on the other hand managers believe their partner to be under-specified, as Table 2B illustrates, they can minimize exploration losses by using the modular mode when in a lower interdependence situation (Patterns 2 and 3) and by using the ratification mode when in a higher interdependence situation (Patterns 4 and 5). Governance choice thus depends on managers' understanding of their task structure, their partner's level of misspecification, and the ultimate objectives of the alliance (whether this is firm performance itself, achieving high levels of exploration, or avoiding coordination failures).

\section{DISCUSSION}

Our aim in this paper was to use a computational model to understand the implications of incorrect managerial representations of inter-firm task interdependencies in the context of alliance relationships, focusing on the effects of under- and over-specification under varying combinations of true inter-firm task interdependence and modes of alliance governance. We derive three sets of results.

First, we find that managerial misspecification of interdependence structures leads to a decline in firm performance, a result consistent with prior case-based work (Doz [1996]; Sosa et al. [2007]). Our results suggest a number of interesting nuances. We find that while over- and under-specification of interdependence have similar effects on performance, the degree of value loss due to misspecification varies by governance mode. The decline in performance is on average lower for the modular and self-governing alliance modes. This difference in the effect of misspecification on various governance modes has important implications. When both firms 
have a correct understanding of their interdependencies, the integrated mode provides better performance at patterns with higher interdependence (Patterns 4 and 5). As we relax the assumption of a correct understanding, however, we find that the self-governing alliance mode provides better performance than the integrated mode. The degree to which firms have an understanding of their underlying interdependencies is thus important in deciding on the optimal mode of governance.

A second set of results is that the pattern of interdependence has a crucial impact on the level of decline in alliance performance due to misspecification. Interestingly, the decline in performance decreases with an increase in the degree of interdependence in the underlying task structure. As illustrated in Tables $1 \mathrm{~A}$ and $1 \mathrm{~B}$, the value loss for the alliance is lowest with Patterns 4 and 5 for both forms of misspecification. We are able to explain these results using the intermediate measures of coordination and exploration.

Our analysis of these intermediate measures leads to our final set of conclusions, which relates to the possibly competing objectives relating to coordination and exploration. Our study lends insight into the consequences of misspecification for these two objectives, as we find that the two forms of misspecification affect each differently. The overall level of exploration achieved by the alliance increases with an over-specified view; in the case of an under-specified view, however, the overall exploration level decreases (though with a few exceptions for low complexity patterns). Similarly, we find that coordination failures increase when both firms share an over-specified view. Although in the case of the under-specified view coordination failures are limited, they decline at higher levels of interdependence. This presents an interesting tradeoff between paying attention to firm performance versus other alliance objectives such as exploration. Firms with an over-specified view of interdependence may achieve higher 
exploration, yet trade this off with lower performance. Likewise, with higher levels of interdependence firms can take on an under-specified view in order to achieve fewer coordination failures.

From a managerial perspective our results underscore the importance of paying attention to task interdependencies when structuring alliances. Decision makers should, in particular, make attempts to identify the true structure of their inter-firm interdependence. While estimating ex ante the magnitude and direction of misspecification may be difficult, managers may be able to reduce the magnitude of such errors by investing in efforts to identify the true interdependence structures in alliances: e.g., pre-alliance discussions and alliance management capabilities can help reduce the likelihood of any misspecifications. Such investments in understanding the true structure become particularly important because, as our results suggest, firms' task structure representations are significant inputs to the choice of alliance governance mode.

Before concluding we discuss some of the assumptions embedded in our model, and their implications for our results. First, our model assumes that both firms are symmetric with respect to their views on interdependence. However, it may not be uncommon to have an alliance where both partners have different views of their interdependencies. We conducted robustness checks to understand the implications of this assumption. As noted in our discussion of coordination and exploration, we evaluated an 'asymmetric view' scenario in which only one of the partner firms has an incorrect view of their interdependence. The overall performance implications were consistent with our main findings, with the magnitude of value loss decreasing when only one partner has an incorrect understanding.

As a second assumption embedded in our analysis, note that we pre-specify firms' understanding regarding their interdependence structure, and assume that this remains constant 
for the entire period (i.e., there is no learning by agents about the true nature of their interdependence). It is likely, however, that firms update their understanding based on feedback received over the course of the alliance. While our purpose in the present paper was solely to examine the implications of relaxing the assumption of a correct specification of inter-firm task interdependencies (a gap that the literature has not yet addressed), it would be a natural extension to relax this assumption and to extend our model in order to study how the process of learning about interdependencies over time (and possibly modifying the alliance governance structure accordingly) influences our results.

As a final assumption, note that we use a pre-defined set of patterns of interdependence to represent task structures and firms' understanding of these structures. The current patterns represent discrete points on the continuum of increasing task complexity. These patterns characterize ideal configuration types that are useful for exposition; hybrid patterns may arise in reality, however, and future research might thus examine such patterns. We did run our results using a "random K" scenario to evaluate the implications of increasing levels of interdependence, where these interdependencies were randomly scattered throughout the task matrix. The results on this analysis were broadly consistent with our findings.

Our paper leads to a number of implications for work in the area of alliance governance. While the issue of governance structure choice has been examined both implicitly and explicitly in the alliance literature, with significant progress being made using empirical indicators, ours is the first effort to attempt to understand the implications of relaxing the common assumption that managers operate with a "true" representation of inter-firm interdependencies. Because in practice managers are unlikely to have perfect ex ante representations of their interdependencies, as we discuss up-front with the example from Doz (1996), such an assumption is likely to be 
unrealistic. Using empirical methods alone, however, is unlikely to allow to us fully address the implications of interdependence misspecifications, as empirical data is unlikely to be structured so as to allow simultaneous and deep observation of managerial representations, interdependencies, and governance structures. As a consequence, computational modeling provides an effective tool with which to examine the implications of managerial errors in interdependence representations in a structured way. The insights we gain from our model can complement future empirical work, and more importantly serve to inform the core theorizing that can guide these future empirical examinations of this topic.

In conclusion, we make an important set of contributions to the literature on alliance governance by highlighting how a partial understanding of task interdependencies can be detrimental for alliance performance. We go beyond prior work to explicitly study the effect of errors on various patterns of interdependence, a task that would be difficult to accomplish using empirical methods alone. In so doing we contribute to the literature on governance choice (e.g. Dyer et al., 2004; Villalonga and McGahan, 2005), shedding new insights into the link between interdependence, governance modes, and firm performance in alliance settings, and offering a promising set of avenues for future research. 


\section{REFERENCES}

Aggarwal VA, Siggelkow N, Singh H. 2011. Governing collaborative activity: interdependence and the impact of coordination and exploration. Strategic Management Journal 32(7): 705-730.

Anand BN, Khanna T. 2000. Do firms learn to create value? The case of alliances. Strategic Management Journal 21(3): 295-315.

Argyres N, Mayer KJ. 2007. Contract design as a firm capability: An integration of learning and transaction cost perspectives. Academy of Management Review 32(4), 1060-1077.

Carson SJ, Madhok A, Wu T. 2006. Uncertainty, opportunism, and governance: The effects of volatility and ambiguity on formal and relational contracting. Academy of Management Journal 49(5): 10581077.

Child J. 2001. Learning through strategic alliances. Handbook of organizational learning and knowledge. Oxford University Press: Oxford, UK.

Doz YL. 1996. The evolution of cooperation in strategic alliances: initial conditions or learning processes? Strategic Management Journal 17(S1): 55-83.

Dyer JH, Kale P, Singh H. 2004. When to ally and when to acquire. Harvard Business Review 82(7-8): 108-115.

Gavetti G, Levinthal D. 2000. Looking forward and looking backward: Cognitive and experiential search. Administrative Science Quarterly 45(1): 113-137.

Gokpinar B, Hopp WJ, Iravani SM. 2010. The impact of misalignment of organizational structure and product architecture on quality in complex product development. Management Science 56(3): 468-484.

Grant RM, Baden-Fuller C. 2004. A knowledge accessing theory of strategic alliances. Journal of Management Studies 41(1): 61-84.

Gulati R, Lawrence PR, Puranam, P. 2005. Adaptation in vertical relationships: beyond incentive conflict. Strategic Management Journal 26(5): 415-440.

Gulati R, Singh H. 1998. The architecture of cooperation: Managing coordination costs and appropriation concerns in strategic alliances. Administrative Science Quarterly 43(4): 781-814.

Hamel G, Doz YL, Prahalad CK. 1989. Collaborate with your competitors and win. Harvard Business Review 67(1): 133-139.

Haspeslagh PC, Jemison DB. 1991. Managing acquisitions: Creating value through corporate renewal. Free Press: New York

Heath C, Staudenmayer N. 2000. Coordination neglect: How lay theories of organizing complicate coordination in organizations. Research in Organizational Behavior 22: 153-191.

Hennart JF, Reddy S. 1997. The choice between mergers/acquisitions and joint ventures: The case of Japanese investors in the United States. Strategic Management Journal 18(1): 1-12.

Kale P, Dyer JH, Singh H. 2002. Alliance capability, stock market response, and long-term alliance success: the role of the alliance function. Strategic Management Journal 23(8): 747-767.

Kale P, Puranam P. 2004. Choosing equity stakes in technology sourcing relationships: An integrative framework. California Management Review 46(3): 77- 99.

Kale P, Singh H. 2009. Managing strategic alliances: What do we know now, and where do we go from here. Academy of Management Perspectives 23(3): 45-62.

Kauffman S. 1993. The origins of order: Self-organization and selection in evolution. Oxford University Press: New York.

Kim S, Zhao J, Anand J. 2015. Knowledge Complexity and the Performance of Inter-unit Knowledge Transfer Structures. Working paper.

Kogut B, Singh H. 1988. The effect of national culture on the choice of entry mode. Journal of International Business Studies 19(3): 411-432.

Kretschmer T, Puranam P. 2008. Integration through incentives within differentiated organizations. Organization Science 19(6), 860-875. 
Lavie D, Rosenkopf L. 2006. Balancing exploration and exploitation in alliance formation. Academy of Management Journal 49(4): 797-818.

Levinthal DA. 1997. Adaptation on rugged landscapes. Management Science 43(7): 934-950.

Litwalk E, Hylton LF. 1962. Interorganizational analysis: A hypothesis on coordinating agencies. Administrative Science Quarterly 6: 395-420.

Lunnan R, Haugland SA. 2008. Predicting and measuring alliance performance: a multidimensional analysis. Strategic Management Journal 29(5): 545-556

Martignoni D, Menon A, Siggelkow N. 2015. Consequences of misspecified mental models: Contrasting effects and the role of cognitive fit. Strategic Management Journal, forthcoming.

Mayer KJ, Argyres NS. 2004. Learning to contract: Evidence from the personal computer industry. Organization Science 15(4), 394-410.

Mayer KJ, Teece DJ. 2008. Unpacking strategic alliances: The structure and purpose of alliance versus supplier relationships. Journal of Economic Behavior and Organization 66(1): 106-127.

Reuer JJ, Arino A. 2007. Strategic alliance contracts: Dimensions and determinants of contractual complexity. Strategic Management Journal 28(3), 313.

Reuer JJ, Devarakonda S. 2015. Mechanisms of hybrid governance: Administrative committees in nonequity alliances. Academy of Management Journal, forthcoming.

Ring PS, Van de Ven AH. 1994. Developmental processes of cooperative interorganizational relationships. Academy of management review 19(1), 90-118.

Rivkin JW. 2000. Imitation of complex strategies. Management Science 46(6): 824-844.

Rivkin JW, Siggelkow N. 2003. Balancing search and stability: Interdependencies among elements of organizational design. Management Science 49(3): 290-311.

Rivkin JW, Siggelkow N. 2007. Patterned interactions in complex systems: Implications for exploration. Management Science 53(7), 1068-1085.

Sampson R. 2004. The cost of misaligned governance in R\&D alliances. Journal of Law, Economics, and Organization 20 (2): 484-526.

Siggelkow N, Rivkin JW. 2005. Speed and search: Designing organizations for turbulence and complexity. Organization Science 16(2):101-22.

Sosa ME, Eppinger SD, Rowles CM. 2004. The misalignment of product architecture and organization structure in complex product development. Management Science 50 (12): 1674-1689.

Sosa ME, Eppinger SD, Rowles CM. 2007. Are your engineers talking to one another when they should? Harvard Business Review 85 (11): 133-142.

Villalonga B, McGahan AM. 2005. The choice among acquisitions, alliances, and divestitures. Strategic Management Journal 26(13): 1183-1208.

Zellner A.1962. An Efficient Method of Estimating Seemingly Unrelated Regressions and Tests for Aggregation Bias. Journal of the American Statistical Association. 57: 348-368.

Zellner A. 1963. Estimator for Seemingly Unrelated Regressions: Some Exact Finite Sample Results. Journal of the Americal Statistical Association 58: 977-992.

Zollo M, Reuer JJ, Singh H. 2002. Interorganizational routines and performance in strategic alliances. Organization Science 13(6): 701-713. 
Figure 1. Interaction matrix example

Firm 1

Firm 2

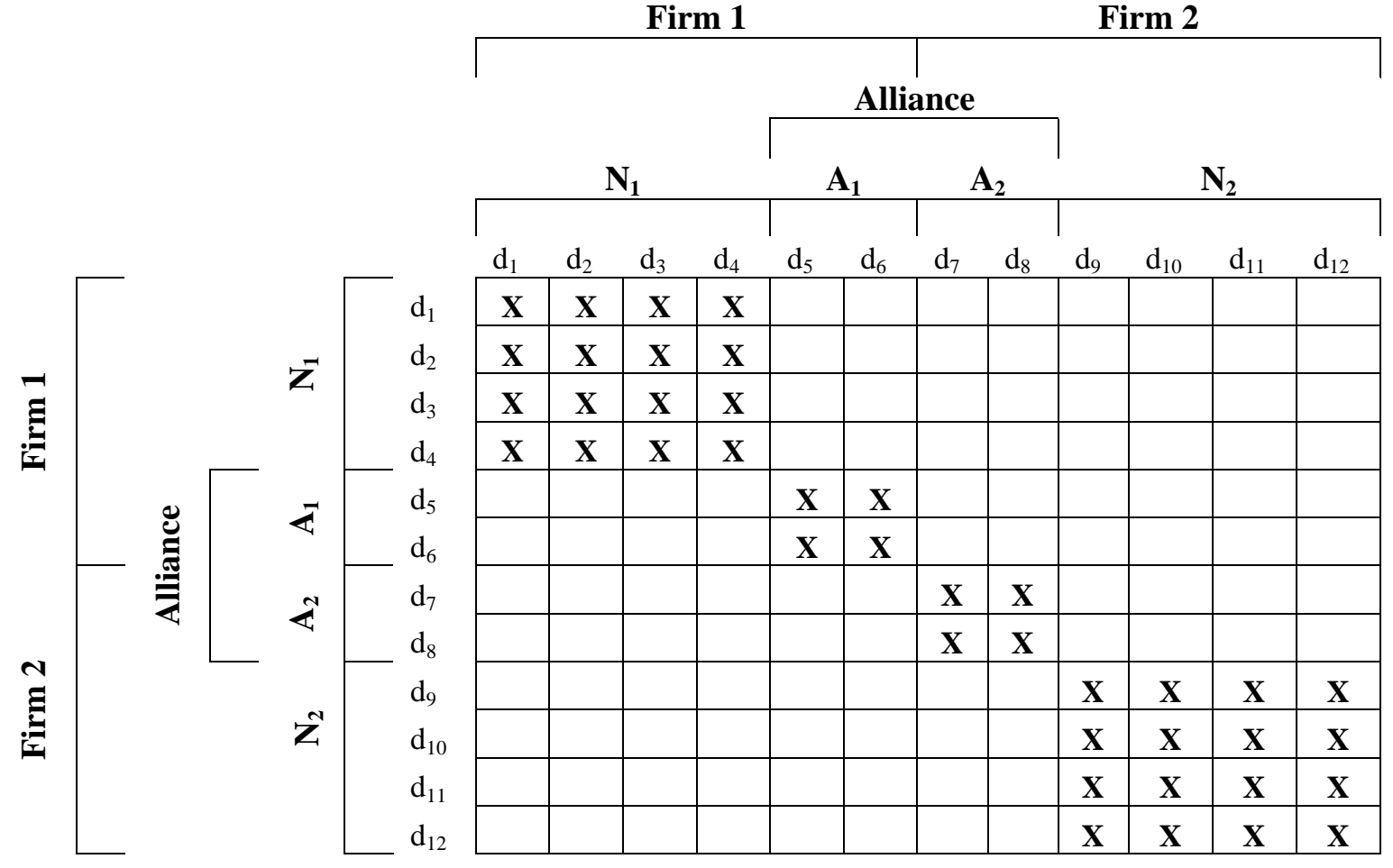

Note: This example corresponds to "Pattern 1" as described in Figure 2 
Figure 2. Patterns of interdependence

Pattern 1:

Fully decomposable

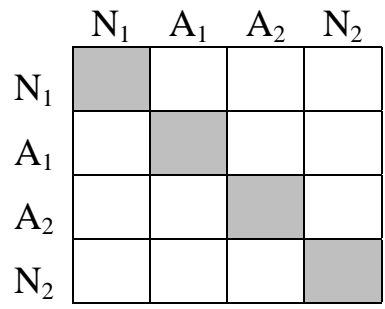

Pattern 4:

Firm partner-alliance interaction

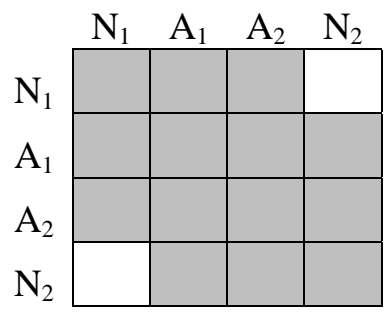

Pattern 2:

Pure alliance interaction

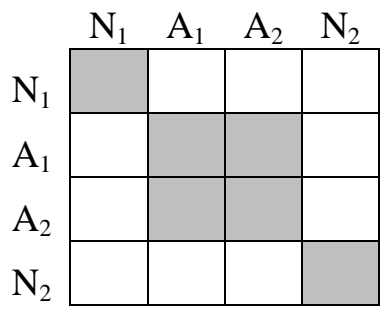

Pattern 5:

Full interdependence

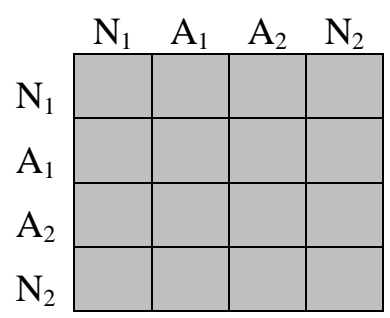

Pattern 3:

Firm own-alliance interaction

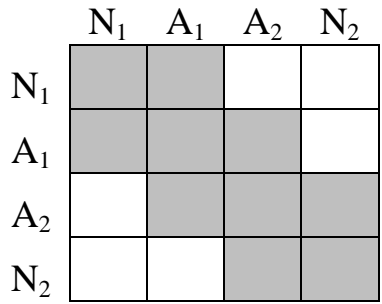

Figure 3: Framework for understanding the effect of misspecification

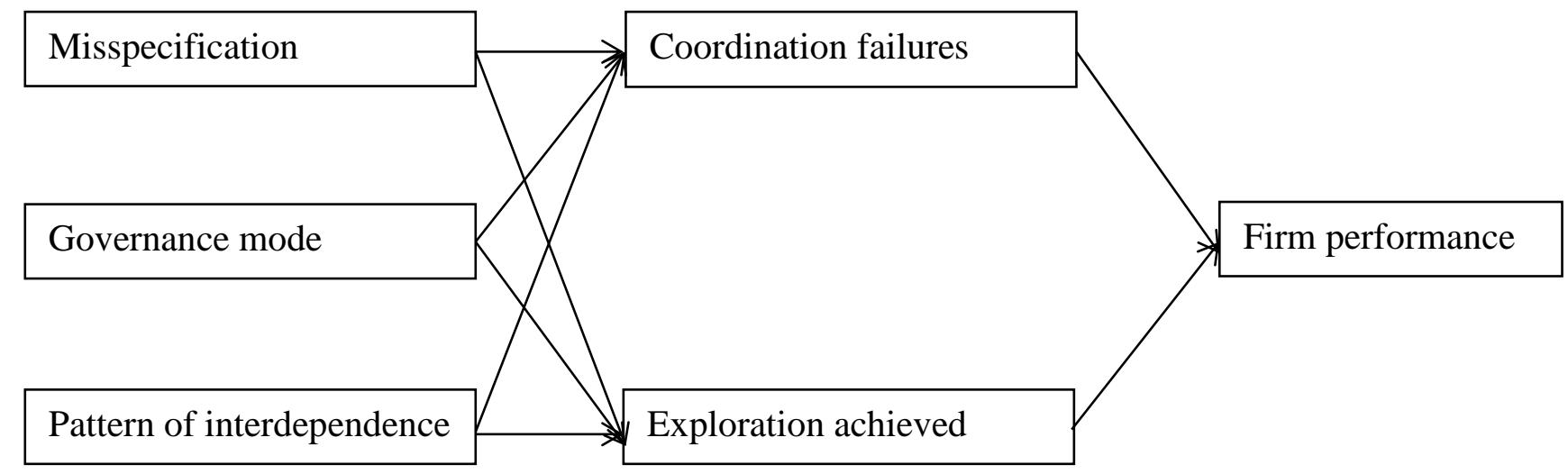


Table 1A. Value loss, over-specified representation

\begin{tabular}{clccc}
\hline $\begin{array}{c}\text { Underlying } \\
\text { pattern }\end{array}$ & $\begin{array}{c}\text { Governance } \\
\text { mode }\end{array}$ & $\begin{array}{c}\text { Performance with } \\
\text { correct view }\end{array}$ & $\begin{array}{c}\text { Performance with } \\
\text { over-specified view }\end{array}$ & \% value loss \\
\hline Pattern 1 & Modular & 0.991 & $\mathbf{0 . 9 4 9}$ & $-4.1 \%$ \\
& Self-Governing & $\mathbf{0 . 9 9 3}$ & 0.927 & $-6.8 \%$ \\
& Ratification & $\mathbf{0 . 9 9 3}$ & 0.912 & $-8.0 \%$ \\
& Integrated & 0.989 & 0.926 & $-6.4 \%$ \\
\hline Pattern 2 & Modular & 0.948 & 0.771 & $-18.6 \%$ \\
& Self-Governing & $\mathbf{0 . 9 8 9}$ & $\mathbf{0 . 8 4 2}$ & $-15.0 \%$ \\
& Ratification & $\mathbf{0 . 9 8 9}$ & 0.802 & $-18.8 \%$ \\
& Integrated & 0.986 & 0.785 & $-20.0 \%$ \\
\hline Pattern 3 & Modular & $\mathbf{0 . 9 5 0}$ & 0.783 & $-17.0 \%$ \\
& Self-Governing & 0.932 & $\mathbf{0 . 7 9 3}$ & $-14.9 \%$ \\
& Ratification & 0.908 & 0.765 & $-15.2 \%$ \\
& Integrated & 0.949 & 0.763 & $-19.5 \%$ \\
\hline Pattern 4 & Modular & 0.884 & 0.747 & $-14.8 \%$ \\
& Self-Governing & 0.884 & $\mathbf{0 . 8 4 5}$ & $-4.6 \%$ \\
& Ratification & 0.879 & 0.803 & $-8.3 \%$ \\
& Integrated & $\mathbf{0 . 9 2 2}$ & 0.816 & $-11.3 \%$ \\
\hline
\end{tabular}

Table 1B. Value loss, under-specified representation

\begin{tabular}{clccc}
\hline $\begin{array}{c}\text { Underlying } \\
\text { pattern }\end{array}$ & \multicolumn{1}{c}{$\begin{array}{c}\text { Governance } \\
\text { mode }\end{array}$} & $\begin{array}{c}\text { Performance with } \\
\text { correct view }\end{array}$ & $\begin{array}{c}\text { Performance with } \\
\text { over-specified view }\end{array}$ & \% value loss \\
\hline Pattern 2 & Modular & 0.944 & 0.921 & $-2.6 \%$ \\
& Self-Governing & $\mathbf{0 . 9 9 0}$ & $\mathbf{0 . 9 2 8}$ & $-6.2 \%$ \\
& Ratification & $\mathbf{0 . 9 9 0}$ & 0.918 & $-7.2 \%$ \\
& Integrated & 0.985 & 0.919 & $-6.6 \%$ \\
\hline Pattern 3 & Modular & $\mathbf{0 . 9 5 0}$ & $\mathbf{0 . 7 7 3}$ & $-19.1 \%$ \\
& Self-Governing & 0.931 & $\mathbf{0 . 7 7 3}$ & $-17.3 \%$ \\
& Ratification & 0.902 & 0.770 & $-15.6 \%$ \\
& Integrated & 0.949 & 0.751 & $-21.6 \%$ \\
\hline Pattern 4 & Modular & 0.873 & 0.745 & $-15.6 \%$ \\
& Self-Governing & $\mathbf{0 . 8 8 4}$ & $\mathbf{0 . 7 9 5}$ & $-10.3 \%$ \\
& Ratification & 0.877 & 0.755 & $-14.7 \%$ \\
& Integrated & 0.927 & 0.749 & $-19.0 \%$ \\
\hline Pattern 5 & Modular & 0.747 & 0.808 & $7.8 \%$ \\
& Self-Governing & 0.828 & $\mathbf{0 . 8 2 9}$ & $-1.0 \%$ \\
& Ratification & 0.780 & 0.757 & $-2.5 \%$ \\
& Integrated & $\mathbf{0 . 9 1 0}$ & 0.823 & $-9.5 \%$ \\
\hline
\end{tabular}

Note: Values in bold indicate the governance mode providing superior performance for each combination of pattern and managerial representation (either correct or misspecified). For example, in Table 1A, with the combination of [Pattern 1, Correct View], both the self-governing and ratification modes provide the highest performance. 
Table 2A: Changes in coordination and exploration, over-specified representation

\begin{tabular}{llcccc}
\hline Underlying & Governance & \multicolumn{2}{c}{ Symmetric view } & \multicolumn{2}{c}{ Asymmetric view } \\
\cline { 2 - 6 } pattern & mode & Exploration & Coordination & Exploration & Coordination \\
\hline Pattern 1 & Modular & $0.9 \%$ & $0.0 \%$ & $0.7 \%$ & $0.0 \%$ \\
& Self-Governing & $3.4 \%$ & $0.0 \%$ & $-0.9 \%$ & $0.0 \%$ \\
& Ratification & $2.3 \%$ & $0.0 \%$ & $-0.6 \%$ & $0.0 \%$ \\
& Integrated & $1.6 \%$ & $0.0 \%$ & - & - \\
\hline Pattern 2 & Modular & $0.6 \%$ & $-14.3 \%$ & $1.6 \%$ & $-5.6 \%$ \\
& Self-Governing & $5.3 \%$ & $0.0 \%$ & $0.3 \%$ & $0.0 \%$ \\
& Ratification & $0.5 \%$ & $0.0 \%$ & $0.3 \%$ & $0.0 \%$ \\
& Integrated & $1.8 \%$ & $0.0 \%$ & - & - \\
\hline Pattern 3 & Modular & $7.7 \%$ & $0.1 \%$ & $2.6 \%$ & $2.4 \%$ \\
& Self-Governing & $9.4 \%$ & $3.5 \%$ & $0.9 \%$ & $1.0 \%$ \\
& Ratification & $0.2 \%$ & $6.2 \%$ & $-0.3 \%$ & $5.9 \%$ \\
& Integrated & $3.7 \%$ & $0.0 \%$ & - & - \\
\hline Pattern 4 & Modular & $3.4 \%$ & $-0.5 \%$ & $0.7 \%$ & $2.5 \%$ \\
& Self-Governing & $0.5 \%$ & $1.6 \%$ & $0.4 \%$ & $0.9 \%$ \\
& Ratification & $0.3 \%$ & $3.9 \%$ & $0.0 \%$ & $4.1 \%$ \\
& Integrated & $1.6 \%$ & $0.0 \%$ & - & - \\
\hline
\end{tabular}

Table 2B: Changes in coordination and exploration, under-specified representation

\begin{tabular}{llcccc}
\hline Underlying & Governance & \multicolumn{2}{c}{ Symmetric view } & \multicolumn{2}{c}{ Asymmetric view } \\
\cline { 2 - 6 } pattern & mode & Exploration & Coordination & Exploration & Coordination \\
\hline Pattern 2 & Modular & $-1.4 \%$ & $-11.7 \%$ & $-0.5 \%$ & $-10.0 \%$ \\
& Self-Governing & $0.6 \%$ & $0.0 \%$ & $-1.6 \%$ & $0.0 \%$ \\
& Ratification & $0.1 \%$ & $0.0 \%$ & $-1.4 \%$ & $0.0 \%$ \\
& Integrated & $-1.2 \%$ & $0.0 \%$ & - & - \\
\hline Pattern 3 & Modular & $2.3 \%$ & $1.1 \%$ & $0.1 \%$ & $1.0 \%$ \\
& Self-Governing & $-1.8 \%$ & $3.4 \%$ & $-0.8 \%$ & $0.5 \%$ \\
& Ratification & $1.3 \%$ & $5.1 \%$ & $0.1 \%$ & $3.6 \%$ \\
& Integrated & $3.0 \%$ & $0.0 \%$ & - & - \\
\hline Pattern 4 & Modular & $-2.1 \%$ & $-11.0 \%$ & $-1.8 \%$ & $-8.7 \%$ \\
& Self-Governing & $-0.6 \%$ & $2.4 \%$ & $-0.5 \%$ & $0.1 \%$ \\
& Ratification & $0.0 \%$ & $4.6 \%$ & $-0.1 \%$ & $0.9 \%$ \\
& Integrated & $1.1 \%$ & $0.0 \%$ & - & - \\
\hline Pattern 5 & Modular & $-2.6 \%$ & $-24.3 \%$ & $-1.7 \%$ & $-17.6 \%$ \\
& Self-Governing & $-1.3 \%$ & $-1.1 \%$ & $-0.9 \%$ & $-1.8 \%$ \\
& Ratification & $-0.6 \%$ & $-13.9 \%$ & $-0.4 \%$ & $-12.1 \%$ \\
& Integrated & $0.0 \%$ & $0.0 \%$ & - & - \\
\hline
\end{tabular}


Table 3: Effect of misspecification on exploration, coordination failure and total profits

\begin{tabular}{|c|c|c|c|}
\hline $\begin{array}{l}\text { Dependent } \\
\text { variable }\end{array}$ & $\begin{array}{l}\text { Independent variable } \\
\text { (all dummy variables } \\
\text { except for constant) }\end{array}$ & $\begin{array}{c}\text { Model } 1 \\
\text { (Over- } \\
\text { specification) }\end{array}$ & $\begin{array}{l}\text { Model } 2 \\
\text { (Under- } \\
\text { specification) }\end{array}$ \\
\hline \multirow[t]{10}{*}{ Exploration } & Misspecification & 0.098 & -0.009 \\
\hline & Self-governing & -0.147 & -0.221 \\
\hline & Ratification & -0.234 & -0.250 \\
\hline & Integrated & 1.055 & 0.787 \\
\hline & Pattern 1 & 0.293 & \\
\hline & Pattern 3 & -1.053 & -1.328 \\
\hline & Pattern 4 & -1.629 & -1.958 \\
\hline & Pattern 5 & & -1.988 \\
\hline & Constant & 0.379 & 1.244 \\
\hline & $\mathrm{R}^{2}$ & 0.874 & 0.818 \\
\hline \multirow[t]{10}{*}{ Coord. failures } & Misspecification & 0.003 & -0.193 \\
\hline & Self-governing & -0.694 & -0.801 \\
\hline & Ratification & -0.600 & -0.561 \\
\hline & Integrated & -0.768 & -0.916 \\
\hline & Pattern 1 & -0.278 & \\
\hline & Pattern 3 & -0.077 & -0.081 \\
\hline & Pattern 4 & 0.282 & 0.117 \\
\hline & Pattern 5 & & 0.478 \\
\hline & Constant & 0.532 & 0.537 \\
\hline & $\mathrm{R}^{2}$ & 0.132 & 0.179 \\
\hline \multirow[t]{9}{*}{ Performance } & Exploration & 0.383 & 0.459 \\
\hline & Coordination failures & -0.212 & -0.375 \\
\hline & Misspecification & -1.116 & -0.830 \\
\hline & Self-governing & 0.116 & 0.012 \\
\hline & Ratification & -0.005 & -0.127 \\
\hline & Integrated & -0.423 & -0.445 \\
\hline & Constant & 0.636 & 0.555 \\
\hline & $\mathrm{R}^{2}$ & 0.413 & 0.390 \\
\hline & Observations & 320,000 & 320,000 \\
\hline
\end{tabular}

Note: All independent variables are dummy variables, except for exploration, coordination failures, and the constant. The misspecification dummy variable refers to the over-specified view for Model 1 and to the underspecified view for Model 2. 